\title{
Detecting Changes in Surface Soil Moisture Content using Differential SAR Interferometry (DInSAR)
}

\author{
B. BARRETT ${ }^{1} \uparrow$, P. WHELAN $\uparrow$ and E. DWYER $\uparrow$ \\ $\uparrow$ School of Biological, Earth and Environmental Sciences, University College Cork \\ (UCC), Butler Building, Distillery Fields, North Mall, Cork, Ireland \\ †Coastal \& Marine Resources Centre (CMRC), University College Cork (UCC), Irish \\ Naval Base, Haulbowline, Co. Cork, Ireland
}

The feasibility of measuring changes in surface soil moisture content with differential interferometric SAR (DInSAR) has received little attention in comparison to other active microwave techniques. In this study, multi-polarisation C- and L-band DInSAR is explored as a potential tool for the measurement of changes in surface soil moisture in agricultural areas. Using ten ascending Phased Array L-band Synthetic Aperture Radar (PALSAR) scenes acquired by the Japanese Advanced Land Observing Satellite (ALOS) satellite and twelve descending Advanced Synthetic Aperture Radar (ASAR) scenes acquired by the European ENVISAT satellite between July 2007 and November 2009, a series of 27 differential interferograms covering a common study area over southern Ireland were generated to investigate whether small-scale changes in phase are linked to measured soil moisture changes. Comparisons of observed mean surface displacement and in-situ mean soil moisture change show that C-band HV polarisation pairs displayed the highest correlation coefficients over both the barley $(\mathrm{r}=0.51, \mathrm{p}=$ $0.04)$ and potato crop $(r=0.81, p=0.003)$ covered fields. Current results support the hypothesis that a soil moisture phase contribution exists within differential interferograms covering agricultural areas.

\section{Introduction}

Soil moisture content influences a variety of processes related to the efficient functioning of the Earth system. It exerts a strong control on the soil physical properties affecting vegetation growth, erosion, runoff and infiltration, as well as on the soil biogeochemistry, influencing microbial activity and $\mathrm{CO}_{2}$ production (by means of respiration). It is also strongly linked to evaporation and the distribution of heat fluxes from the land to the atmosphere and is identified as an essential climate variable (ECV), of fundamental importance in the study of climatology and meteorology. All of these processes impact on social and economic activities. Yet, despite its importance, soil moisture has not been widely used as a variable in the hydrological, ecological, agricultural and climatic models where it is implicated. This is due to its large spatial

\footnotetext{
${ }^{1}$ Corresponding author. E-mail: bbarrett@ucc.ie
} 
and temporal inhomogeneity and the inadequacy of sparse ground-based measurements to characterise the soil moisture content at these scales. The traditional use of point measurements is essentially meaningless unless dense networks of in-situ monitoring stations are established (Van Oevelen, 1998). Spaceborne microwave remote sensing has the capability to monitor soil moisture over large areas at regular intervals in time and several approaches for soil moisture retrieval have been developed over the past three decades using this technology (Barrett et al. 2009; Wigneron et al. 2003).

However, the majority of soil moisture retrieval studies using synthetic aperture radar (SAR) use only the amplitude part of the received echo. The use of the phase component and the potential of interferometric SAR (InSAR) to obtain soil moisture information remain largely unrealised.

InSAR is an established technique for the generation of Digital Elevation Models (DEMs) (Zebker and Goldstein, 1986) as it measures the phase difference between two SAR images, acquired at the same time (single-pass InSAR) or at different times (repeat-pass InSAR), and slightly different viewing geometries to produce an interferogram and subsequently enable the extraction of 3D topography from within the imaged scene. Differential SAR Interferometry (DInSAR) is an advancement of the InSAR technique that is used to measure precise surface displacements on the Earth`s surface, such as those associated with earthquakes, landslides or subsidence (Fruneau et al. 1996; Massonnet and Feigl, 1995; Massonnet et al. 1993; Rott et al. 1999) that occur between two different satellite passes. It has been shown by Alsdorf et al. (2000) and Alsdorf et al. (2001a) that DInSAR techniques can also produce centimetre-scale measurements of water level changes over inundated vegetation such as in swamps and wetlands. These studies used L-band HH polarisation SAR data from the Shuttle Imaging Radar (SIR-C) mission with a temporal baseline of only 24 hours, however the same capability has also been demonstrated using Japanese Earth Resources Satellite (JERS-1) data with a 44 day temporal baseline (Alsdorf et al. 2001b). Similarly, Lu and Kwoun (2008) used shorter wavelength European Remote Sensing 1 \& 2 (ERS-1/2) and Radarsat-1 data to map water-level changes beneath a swamp forest in Louisiana successfully.

Very few studies have been published to date that have been dedicated to the detection of soil moisture changes using spaceborne DInSAR. The first demonstration that DInSAR phase could contain a soil moisture signal was by Gabriel et al. (1989) using L-band Seasat data over agricultural test sites in California where they suggested that the abrupt changes in phase observed at field boundaries could be explained by variations in soil moisture. Their rationale was that increases and decreases in water content caused expansion and contraction in clay dominated soils that could be measured by DInSAR. This was confirmed when irrigation patterns for the fields in question were found to correspond with the apparent increases and decreases in the soil surface. Similarly Boyle et al. (2000) used tandem ERS 1 \& 2 differential interferograms and soil moisture deficit data to monitor clay shrinkage and swelling over London for applications in structural damage management and water resource conservation. Nolan and Fatland (2003) later suggested the use of DInSAR penetration depth as a viable proxy for soil moisture estimation. Their hypothesis was based on the fact that soil moisture variations can cause a change in path length (penetration depth), independent of the soil type, and thus induce a change in the observed phase scattering center. Further investigation by Nolan et al. (2003) demonstrated the use of C-band DInSAR in the measurement of soil moisture, though their results could not 
quantitatively verify that differences in soil moisture were the cause of the observed phase variations.

Various airborne DInSAR (e.g. Hajnsek and Prats 2008; Prats et al. 2007; Reigber and Scheiber 2003) and laboratory controlled (e.g. Khadhra et al. 2006; Morrison et al. 2008) investigations using multiple frequencies have produced similar findings to the spaceborne campaigns mentioned above. For example Reigber and Scheiber (2003) found changes in surface elevations over agricultural test sites in Oberpfaffenhofen to be related to soil moisture changes, using the German Aerospace Centre (DLR) airborne experimental SAR system (E-SAR). Similarly, Prats et al. (2007) presented differential SAR results, acquired by the E-SAR system, where the areas of detected deformation correlated well with the shapes of agricultural fields, concluding that the most plausible explanation for these effects is a change in soil moisture. More recently Rabus et al. (2010) presented the theoretical support for linking the DInSAR phase and soil moisture through numerical modelling.

There exists an enormous amount of experience with spaceborne C-band DInSAR based on ERS-1, ERS-2, ENVISAT ASAR and Radarsat 1 \& 2 data. L-band DInSAR, however, has been less well explored. Since JERS-1 ceased functioning in 1998, no operational spaceborne L-band SAR existed until the launch of ALOS in early 2006, creating an almost nine year gap in the continuity of L-band data. The ALOS PALSAR sensor has numerous factors that improve the quality of L-band DInSAR including a high signal-to-noise (SNR) ratio, narrow orbital tube $(\sim 1 \mathrm{~km}$, i.e. short perpendicular baselines), accurate orbital information and increased spatial resolution. L-band is particularly attractive for detecting phase changes due to soil moisture differences in agricultural fields because of its reduced susceptibility to temporal decorrelation over vegetated areas. C-band on the other hand, due to its shorter wavelength, is influenced to a greater extent by the presence of vegetation cover and decorrelates more rapidly. The main focus of this study is to compare the use of a number of repeat-pass $\mathrm{C}$ - and L-band co- and cross-polarised differential interferograms with varying spatial and temporal baselines in investigating whether calculated path length changes correspond to variations in measured soil moisture over agricultural fields. The various other possible contributors to the phase variation are also explored and discussed.

\section{Study Area and Data}

\subsection{Study Area Characteristics}

The selected study site is located on Great Island, Cork, Ireland (Lat. $51^{\circ} 52^{`} \mathrm{~N}$ and Long. $\left.-8^{\circ} 16^{\circ} \mathrm{E}\right)$ and classed predominantly as agricultural. The region has an annual average rainfall of between $1100 \mathrm{~mm}$ and $1250 \mathrm{~mm}$ and generally high humidity, averaging $\sim 90 \%$ throughout the year. Figure 1 represents the swath coverage of the ASAR (red polygons) and PALSAR (black polygon) data acquired for this study. The aspect of all study fields is a north-south direction with minimal slopes, rendering both ascending and descending data suitable for DInSAR analysis. The AVNIR-2 image subset in figure 1 displays the location of the three study fields. In 2007 and 2008, barley was cultivated in field A. In 2009, potatoes were cultivated in the northern half 
and barley in the southern half. Field B was planted with potato in 2008 and barley in 2009. Field C was used to grow potatoes in 2007 and 2009 and barley in 2008.

\section{FIGURE 1}

\subsection{SAR data}

\section{TABLE 1}

The key characteristics of both the ASAR and PALSAR sensors are listed in table 1. A total of ten PALSAR images, seven scenes in Fine Beam Dual (FBD) mode (HH/ HV polarisation) and three scenes in Fine Beam Single (FBS) mode (HH polarisation) and twelve scenes in ASAR Alternating Polarisation (APS) mode (HH/HV and HH/VV polarisation) acquired from 2007 to 2009 were used for this study. All SAR data were provided by the European Space Agency (ESA). Six of the ASAR APS scenes were acquired in $\mathrm{HH} / \mathrm{HV}$ dual polarisation mode with an incidence angle of $\sim 19^{\circ}$ and three with an incidence angle of $\sim 23^{\circ}$ with the remaining three scenes in HH/VV polarisation with an incidence angle of $\sim 23^{\circ}$. The PALSAR scenes were acquired with an incidence angle of $\sim 38^{\circ}$ and have a $70-\mathrm{km}$ swath width. The pixel spacing for the FBS data is $4.68 \mathrm{~m}$ in range and $3.17 \mathrm{~m}$ in azimuth direction, compared to $9.36 \mathrm{~m}$ in range and $3.17 \mathrm{~m}$ in azimuth for the FBD mode. The ASAR data have a 100-km swath width and a sample spacing of $7.80 \mathrm{~m}$ in range and $4.05 \mathrm{~m}$ in azimuth. The perpendicular baselines of the PALSAR scenes ranged from 419-1156m and the temporal baselines from 46-92 days. The ASAR scenes had perpendicular baselines ranging from 43-571m and temporal baselines from 35 - 70 days. From this dataset, eleven ASAR, ten PALSAR FBD, three PALSAR FBS and three mixed mode-FBD2FBS interferograms were generated (see table 2). The selection of these pairs was based on the physical separation between the orbits (perpendicular baseline) being as small as possible, the time interval between the acquisitions (temporal baseline) being as short as possible and the difference in the Doppler centroid frequency being below $\sim 50 \mathrm{~Hz}$ (i.e. to ensure the Doppler spectra overlap) to minimise decorrelation.

\section{TABLE 2}

\subsection{In-situ measurements}

Simultaneous to the SAR acquisitions, ground measurements of volumetric soil moisture and crop height were carried out at eight sampling sites per field within four hours of the satellite overpass. Photographs of each field in the direction of crop row were taken during each overpass. Field A has a silty clay soil texture, field B: clay loam and field C: silty loam. At each sampling site, average soil moisture was calculated from a minimum of three replicate measurements at depths of $0-6 \mathrm{~cm}$ taken within $50 \mathrm{~cm}$ of the centre of the sampling site. Soil moisture was measured using the Stevens Hydra Probe II (Seyfried and Murdock, 2004) connected to a PDA to record the measurements. The Hydra Probe has a reported accuracy of $+/-3 \%$ soil moisture. 


\section{Methodology}

The principle behind DInSAR measurement of soil moisture is based on the relationship between the signal penetration depth and dielectric constant, which varies as a function of soil moisture content. A time series of 27 differential interferograms over the study area were generated to analyse whether the observed phase values contain a soil moisture signal by comparing the calculated path length changes (converted to vertical displacements) with in-situ measured soil moisture changes. All statistical calculations were performed using PASW/SPSS 17®. No field measurements were collected on $15 / 01 / 2008$ and 26/08/2008 and consequently pairs using these acquisitions could not be included in the comparison. A coherence analysis was performed at first to determine the suitability of the differential interferograms generated using different sensor parameters, temporal and spatial baselines.

The variation of phase throughout the image scene is representative of the variations in the antenna-ground path length difference between the two images (Peltzer et al. 1998). Due to the slightly different viewing geometry of both image acquisitions, the phase is sensitive to the topography within the scene due to the parallax between the two different lines-of-sight (LOS). The phase is also sensitive to any surface displacement (along the radar line-of-sight or slant-range direction) that occurred during the time interval between acquisitions, along with different atmospheric conditions at the time of acquisition and system noise (Massonnet and Feigl, 1998). DInSAR isolates the surface displacement phase signal by minimising all other contributions to the phase. Each phase cycle or fringe ( $2 \pi$ radians) that remains in the resulting differential interferogram represents half the sensor wavelength of displacement (relative to the satellite) along the radar line-of-sight (Massonnet et al. 1993). In the case of ASAR, for example, $2 \pi$ displacement phase corresponds to $2.8 \mathrm{~cm}$ of displacement along the radar line-of-sight.

Processing of all the pairs was carried out by using the standard two-pass DInSAR method using SARscape ${ }^{\circledR}$ software. Each Single-Look-Complex (SLC) image pair was co-registered to sub-pixel level accuracy and spectral shift and common Doppler bandwidth filtering performed to minimise the baseline-induced decorrelation and eliminate the decorrelation due to the Doppler centroid differences. Multi-looking factors of 1 (in range) and 4 (in azimuth), 1 and 3 and 1 and 6 were used to create quasisquare pixels for the FBD pairs $(15 \mathrm{~m})$, FBS pairs $(10 \mathrm{~m})$ and ASAR pairs $(25 \mathrm{~m})$ respectively. An Ordnance Survey of Ireland (OSi) 10m spatial resolution DEM with vertical accuracy of $\leq 50 \mathrm{~cm}$ was used along with precise orbital data to simulate and subsequently remove the topographic phase from the original interferogram. The differential phase was filtered using the Goldstein filter (Goldstein and Werner, 1998) and unwrapped using a region growing algorithm (Xu and Cumming, 1999) with a coherence threshold of 0.15 applied to minimise unwrapping errors.

The PALSAR FBD mode data have the same centre frequency as the FBS mode but are acquired at half the range bandwidth (i.e. $14 \mathrm{MHz}$ instead of $28 \mathrm{MHz}$ ). The FBD data were therefore over-sampled in range by a factor of two to transform them into the same sample spacing as the FBS mode enabling mixed mode FBD2FBS interferometry. Both scenes were co-registered to a common reference geometry and spectral shift and common band filtering applied to take into account the smaller bandwidth of the FBD scene before the interferogram was generated. The mixed mode pairs were filtered and 
unwrapped as per above. In a final step, the unwrapped differential phase values (with a coherence criterion of greater than 0.3 ) were converted to absolute displacement values and geocoded onto the Irish Grid projection using ground control points and the DEM.

\section{Results \& Discussion}

\subsection{Coherence Analysis}

Low coherence prevents the recovery of reliable phase measurements. In a first step, a quantitative assessment of the interferometric coherence over the study area was carried out. High coherence is expected in areas where the surface does not change much between acquisitions, such as urban areas and rock outcrops, and moderate to low coherence is generally observed over surfaces that do change such as agricultural fields and water bodies. The town of Cobh (visible in the south west of the image subset in figure 1) and the surrounding water areas were excluded from the analysis so that figure 2 displays the mean coherence values calculated for the agricultural areas on the island. As can be seen, the PALSAR data, [figure 2(a) - (b)] have higher coherence than the ASAR data [figure 2(c)]. This is largely attributed to the difference in wavelength between the two sensors, as L-band $(\sim 23 \mathrm{~cm})$ can penetrate deeper through the vegetation cover and consequently maintain higher coherence than $\mathrm{C}$-band $(\sim 5.6 \mathrm{~cm})$. Another salient aspect of the PALSAR L-band sensor is the higher achievable spatial resolution $(10-15 \mathrm{~m})$, compared to ASAR $(25 \mathrm{~m})$. In general, the coherence of the FBD mode data [figure 2(a)] is higher than the FBS and FBD2FBS mode data [figure. 2(b)]. The observed higher coherence may be due to the fact that the FBD and FBS acquisitions were acquired during different seasons (Summer/Autumn and Winter/Spring respectively) rather than the different pixel resolution in each of the modes. In figure 2(a), it is shown that the PALSAR FBD coherence decreases with increasing temporal baseline and increasing perpendicular (spatial) baseline. This inverse relationship is similar to those found by Hong et al. (2010) and Kim et al. (2009). A similar trend of decreasing coherence with increasing temporal and spatial baseline can be seen in figure 2(b). Also interesting to note is the coherence difference between pairs with different polarisations. In all but one of the PALSAR cases, coherence from $\mathrm{HH}$ polarisation pairs is significantly higher than from the corresponding HV polarisation pairs [figure 2(a)]. The Jul-Oct $2009 \mathrm{HH}$ dataset is the one anomalous case. In figure 2(c) all of the ASAR coherence values are considered low $(\gamma<0.3)$, however, the same general trend of higher HH coherence over HV coherence can be observed. The ASAR VV polarisation coherence values are consistent with the $\mathrm{HH}$ polarisation values.

The above coherence analysis suggests that PALSAR FBD images (both $\mathrm{HH}$ and HV) can maintain good coherence $(\gamma>0.45)$ over agricultural areas for one repeatcycle (46 days) and reasonable coherence for two repeat-cycles (92 days). Conversely, ASAR HH, HV and VV polarisation pairs display poor coherence $(\gamma<0.3)$ for one and two repeat-cycles ( 35 and 70 days respectively) over the agricultural areas. The PALSAR FBS and FBD2FBS have intermediary coherence values for both one and two repeat-cycles.

FIGURE 2 


\subsection{Analysis and interpretation of the time series of surface displacement maps}

The ASAR and PALSAR surface displacement maps for the study area are shown in figure 3 and figure 4 respectively. It is assumed that any horizontal movement is negligible and the displacement exhibits an exclusively vertical behaviour ( $\mathrm{Ng}$ et al. 2010; Wegmuller et al. 2000). The maps show displacement magnitude in metres, where negative values correspond to increasing path length changes and positive values relate to decreasing path length changes between sensor and target (i.e. movement towards the sensor). All pixels with coherence values lower than 0.3 in the interferograms have been excluded from the displacement maps. The displacement values are superimposed on the mean intensity image of both acquisitions used to generate the interferometric pair and the colour bar indicates displacement within the scene. The spatial scale of the maps is given in figure 3(1). The field boundary overlays (white polygons) identify the measured displacements within each of the study fields. It is evident in some of the plots that phase variations (which translate into the displayed surface displacements) are present within the field boundaries and may be linked to the fine-scale heterogeneities in soil moisture content. The hypothesis tested in this paper is that increases/decreases in surface soil moisture coexist with decreases/increases in signal path length (and thus, increases/decreases in the surface elevation). Therefore, positive surface displacement values correspond to less signal penetration (and possible clay swelling) as a potential result of an increase in soil moisture. Similarly, negative surface displacement values identify decreases in soil moisture.

As expected, and following from the previous coherence analysis, ASAR HH polarisation data [figure $3(\mathrm{a}),(\mathrm{c}),(\mathrm{e}),(\mathrm{g}),(\mathrm{h}),(\mathrm{i}), \&(\mathrm{k})$ ] produce marginally more valid displacement pixels compared to the HV and VV datasets [figure 3(b), (d), (f), and (j)]. In general, no discernible patterns can be distinguished in the ASAR data and the majority of valid data pixels are sparsely located. In contrast, the PALSAR FBD displacement pixels are less diffuse with the exception of the Jul-Oct HH 2009 pair [figure 4(i)], which could be a result of its long spatial (1064m) and temporal baselines (92 days), along with differences in accumulated precipitation (0.1 vs. $11.6 \mathrm{~mm})$ and wind speed ( 7 vs. 16knots) between the acquisitions. These possible sources of error are discussed further in section 4.3 .

\section{FIGURE 3}

The L-HH polarisation provides better penetration through the vegetation canopies while the L-HV polarisation interacts more with the canopy itself. This is apparent in figure 4 as the $\mathrm{HH}$ pairs [figure 4(a), (c), (e), and (g)] produce more consistent displacement results compared to their respective HV polarisation pairs [figure 4(b), (d), (f), and (h)] that experience greater decorrelation. Irrigation is not required in Irish agriculture as rainfall is usually sufficient (Donnelly et al. 2004), thus clear phase changes occurring between field boundaries as a result of irrigation practices [e.g. as in Gabriel et al. (1989)] are not expected. Nonetheless, distinct field-scale displacements can be observed, for example, in field C [figure 4(a), (j)], and field B [figure 4(1)]. In addition, fields not included in the ground measurements also display, depending on the respective fields, both increases and decreases in surface movement. 
Despite the lack of irrigation, which would cause an abrupt change in soil moisture between field boundaries, soil moisture is still expected to vary between fields (as shown in figure 5) due to differences in evapotranspiration, infiltration and drainage due to varying soil type and farming practices (Nolan et al. 2003). The higher resolution FBS pairs [e.g. figure 4(k), (l), and (m)] clearly reveal some of the individual fields that have completely decorrelated between acquisitions, associated with the mechanical cultivation and sowing of the fields, while the mixed mode pairs [figure 4(n)-(p)] appear more noisy than the FBS and FBD pairs. Overall, it can be observed from figure 3 and 4 that the phase discontinuities and decorrelation are less severe for PALSAR interferograms than for the ASAR interferograms, due in part to the finer resolution and longer wavelength of the PALSAR sensor. As a result, PALSAR FBD and FBS mode have an obvious higher success rate for generating displacement maps.

\section{FIGURE 4}

The plots comparing the mean surface displacement in both HH and HV polarisations for the ASAR and PALSAR FBD pairs with in-situ soil moisture values are displayed in figure 5. Variations in observed displacements between each field for the same pair are apparent with the ASAR $\mathrm{HH}$ and $\mathrm{HV}$ pairs displaying the widest range in values compared to the L-band pairs. The lowest L-band displacements in all three fields are in HV polarisation, contrasting with Hajnsek and Prats (2008) who observed lowest displacements in $\mathrm{HH}$ polarisation over rape, wheat and barley fields.

\section{FIGURE 5}

To quantitatively test the hypothesis that observed surface displacements from the agricultural fields in figure 3 and 4 are linked to surface soil moisture changes, the displacements are correlated with in-situ soil moisture values. The overall results of the correlation analysis along with the results from each interferometric pair are presented in table 3. As no soil moisture measurements were carried out on the $15^{\text {th }} \mathrm{Jan} 2008$, comparisons between DInSAR displacements and soil moisture could not be carried out for the FBS Jan-Mar 2008 and Jan-Apr 2008 pairs and for the FBD2FBS Jan08-Oct07 pair. The ASAR Aug-Nov 2008 pairs were also excluded from the analysis as a consequence of no field measurements on $26^{\text {th }}$ Aug 2008. No correlation results are present for the FBS Mar-Apr 2008 pair as there was an insufficient amount of displacement results (due to decorrelation) to correlate with the soil moisture changes.

\section{TABLE 3}

As can be seen in table 3, the combined ASAR HV pairs display significant ( $\mathrm{p}<$ 0.05 ) positive correlations between surface displacement and measured soil moisture change between acquisitions for both crop types. Similarly, the analysis reveals a moderate positive correlation $(r=0.33, p=0.02)$ for the PALSAR HH pairs over the fields cultivated with barley. In contrast to the ASAR HV pairs, the PALSAR HV pairs display a significant negative correlation between soil moisture change and surface displacement measured over the fields growing barley. The remaining pairs all display non-significant findings. Nolan et al. (2003) found similar non-significant results using 
a ten-month time-series of eight differential interferograms generated using ERS-2 data (C-band VV polarisation).

\subsection{Sources of Error}

The observed displacements over the agricultural fields depend not only on the change in soil moisture but possibly on other various contributors to the interferometric phase signal. In general, the main limitations of repeat-pass DInSAR in reliably measuring surface displacements, apart from total coherence loss, come from the DEM error and atmospheric delays. Over agricultural areas, the impact of the changing crop growth stages must also be taken into account. Since the path-length changes being measured with DInSAR are small, a high resolution DEM or appropriately-small perpendicular baselines must be used to detect them. As can be seen from table 2, not all perpendicular baselines were sufficiently small so a 10m Ordnance Survey of Ireland (OSi) DEM with a vertical accuracy of $0.5 \mathrm{~m}$ was used in this study, thus the effects of DEM errors on the interferograms were considered negligible.

The phase distortions due to atmospheric (ionospheric and tropospheric) effects can significantly reduce the accuracy of the generated surface displacement maps [e.g. see Goldstein (1995) and Zebker et al. (1997)]. The magnitude of the ionospheric effect [e.g. see Xu et al. (2004)] is inversely proportional to the sensor frequency (i.e. more severe for lower frequencies), and due to variations in Total Electron Content (TEC) and travelling ionospheric disturbances (Klees and Massonnet, 1998). The TEC ionospheric delay can be considered uniform throughout the entire SAR image and largely cancels as both acquisitions are taken at the same time of day. The more severe tropospheric effects are independent of frequency and mainly due to changes in the water vapour content between acquisitions (see Ding et al. (2008) for a comprehensive review) and can cause misinterpretation of the observed surface displacements. For example, Zebker et al. (1997) found that changes of $\sim 20 \%$ in the relative humidity of the troposphere could lead to $10 \mathrm{~cm}$ error in observed displacement results. As can be seen from the meteorological conditions recorded at each acquisition date (table 4), two C-band pairs (06/07/2007-10/08/2007, 01/06/2008-06/07/2008) and two L-band pairs (FBS: 15/01/2008-16/04/2008, FBD2FBS: 16/04/2008-01/06/2008) have relative humidity differences between acquisitions of greater than $20 \%$. However, from figure 5 , the C-band Jul-Aug $2007 \mathrm{HH}$ and HV pairs display a negative mean surface displacement linked with a decrease in measured mean soil moisture change in both fields A and C while the Jun-Jul 2008 HH and HV pairs show a positive mean surface displacement linked with an increase in measured mean soil moisture change in all three fields. These findings tie-in with the accumulated three-day precipitation values which show a reduction in recorded precipitation between the three days preceding the $6^{\text {th }}$ July 2007 and $10^{\text {th }}$ Aug 2007 respectively, and also an extreme rise between the three days preceding the $1^{\text {st }}$ June 2008 and the $6^{\text {th }}$ July 2008 acquisitions. In fact, the recorded precipitation values for all dates and all $\mathrm{C}$-band surface displacements showed strong positive correlations for both $\mathrm{HH}$ and $\mathrm{HV}$ pairs over the barley $(\mathrm{HH}: \mathrm{r}=0.86, \mathrm{p}<0.001$, $\mathrm{n}=28$, HV: $\mathrm{r}=0.76, \mathrm{p}<0.001, \mathrm{n}=17)$ and potato crop (HH: $\mathrm{r}=0.76, \mathrm{p}<0.001, \mathrm{n}=33, \mathrm{HV}$ : $\mathrm{r}=0.83, \mathrm{p}=0.003, \mathrm{n}=10)$. In contrast, the only L-band data to display a significant correlation between the recorded precipitation values and surface displacements were the $\mathrm{HH}$ pairs for the potato fields only $(\mathrm{r}=0.38, \mathrm{p}=0.005, \mathrm{n}=51)$. 


\section{TABLE 4}

It is generally regarded that using scenes acquired under anti-cyclonic conditions and/or at night can help reduce atmospheric artefacts more than daytime acquisitions, due to the relative inactiveness of vegetation and a more stable atmosphere at night (Massonnet and Feigl, 1998). All PALSAR scenes used in this study were acquired during nighttime (ascending) passes ( 22:45 UTC) while all ASAR scenes were acquired during daytime (descending) passes ( 11:00 UTC). Given that Ireland has a particularly wet climate (in terms of both volumes and number of days with rain) and is prone to cloud cover, it is possible that a number of the observed surface displacements represent artifacts due to tropospheric water vapour perturbations ( $\mathrm{Lu}, 2007)$. However, the atmospheric phase contribution to interferograms generated in this study was assumed to be insignificant as the spatial extent of the study fields considered here are only of the order of several hundred meters (Carnec et al. 1996; $\mathrm{Ng}$ et al. 2009). Usually, the variation in phase due to atmospheric heterogeneities is typically of the order of several kilometers (Goldstein, 1995). Notwithstanding this, further research is needed in this area to fully understand the atmospheric effects and to develop more effective techniques for their mitigation. For example, the use of the Persistent Scatterers (PS) technique, where scatterers not affected by soil moisture such as rock outcrops or buildings are used, could help reduce the possibility of misinterpreting atmospheric noise as a soil moisture phase signal.

It is possible that the vegetation changes between acquisitions contributed to the surface displacement values observed in figure 3 and 4. For example, Hajnsek and Prats (2008) found a strong correlation between the biomass changes during the crop growing season and observed DInSAR displacements at L-band. However, in the same study, no correlation between vegetation height and displacement was observed over the same crops. Nonetheless, this effect should only be of concern during the summer months as most of the vegetation is invisible to L-band during the early and late growing periods. C-band, on the other hand, is more susceptible to scatterer change as a result of vegetation growth.

Despite these uncertainties and through incorporating a suitable coherence threshold to mitigate against retrieving phase displacements over areas where one or more of the aforementioned sources of errors may have presented, some of the displacement maps show several interesting effects, which may be attributable to soil moisture changes. For example in figure 4(j), field $\mathrm{C}$ displays an average increase in surface elevation of $13 \mathrm{~mm}$ (i.e. a reduction in path length) which corresponds to an average soil moisture increase between acquisitions of $12 \%$. Similarly, field $\mathrm{C}$ in figure 4(a) and field B in figure 4(l) display complete field-scale displacements while field B in figure $4(\mathrm{a}),(\mathrm{e}),(\mathrm{g})$ and $(\mathrm{j})$ display within-field variations.

\section{Conclusions}

Current knowledge of the temporal and spatial dynamics of surface soil moisture is poor. The purpose of this study was to test the suitability of ASAR and PALSAR DInSAR for soil moisture change detection over agricultural areas in southern Ireland at high spatial resolution. A series of differential interferograms were generated to 
determine whether observed phase variations were linked to in-situ soil moisture changes.

PALSAR has a deeper penetration through the vegetation cover and consequently maintains higher coherence. In addition, PALSAR has a higher spatial resolution. Both these qualities led to more definitive displacement maps when compared to the C-band displacement maps [figure 3(a) - (k)]. However, the quantitative analysis shows that $\mathrm{C}$-band displacements in $\mathrm{HV}$ polarisation displayed the highest correlation coefficients $(r=0.51, p=0.04$ and $r=0.81, p=0.003$ respectively) between surface displacements and soil moisture changes over both the barley and potato crop covered fields. It is unlikely the observed C-band surface displacements were related to changes in vegetation height as the signal generally decorrelates between long acquisitions for agricultural areas. Surprisingly, the ASAR HH polarisation pairs displayed no significant correlations, considering $\mathrm{HH}$ polarisation at low incidence angles can generally penetrate vegetation cover better than HV or VV polarisations. The L-band HH polarisation surface displacements however, revealed a moderate link to measured soil moisture changes for just the barley crop covered fields only.

The main limitations of the differential interferometric technique for soil moisture determination were the temporal decorrelation of the signal, which led to incomplete coverage of displacement values, especially in vegetated and agricultural areas. Decorrelated areas in the FBS displacement maps correlated well with field boundaries in the AVNIR-2 image, accentuating those fields that had undergone mechanical cultivation between acquisitions. Soil moisture change detection in these instances was not possible. Despite the complex processing and practical limitations of the technique, repeat-pass DInSAR has the potential, theoretically, to provide information at high-resolution on the spatial and temporal dynamics of surface soil moisture content, yet the results obtained in this analysis do not allow us to assess if this is feasible in practice, and many issues have to be resolved before this is possible. Current generation SAR sensors have a poor temporal resolution; one of the major problems in this study with the ASAR and PALSAR data was the long repeat cycles. Future interferometric satellites such as DESDynl (Donnellan et al. 2008), Tandem-L (Krieger et al. 2009), Sentinel-1 and ALOS-2 with shorter repeat cycles should be able to overcome some of the limitations experienced in this study and should significantly improve the coherence and thus, the potential application of DInSAR for the robust detection of surface soil moisture changes.

\section{Acknowledgements}

The authors would like to thank the European Space Agency for providing the SAR data under AOIreLux project ID4406. The authors would also like to acknowledge the Irish Environmental Protection Agency (EPA) for supporting this research through the Science, Technology, Research and Innovation for the Environment (STRIVE) Programme, financed by the Irish Government under the National Development Plan (NDP) 2007-2013. 


\section{References}

ALSDORF, D., MELACK, J., DUNNE, T., MERTES, L., HESS, L., \& SMITH, L., 2000. Interferometric radar measurements of water level changes on the Amazon flood plain. Nature, 404, pp. 174-177.

ALSDORF, D., SMITH, L., \& MELACK, J., 2001a. Amazon floodplain water level changes measured with interferometric SIR-C radar. IEEE Transactions on Geoscience \& Remote Sensing, 39, pp. 423-431.

ALSDORF, D.E., BIRKETT, C., DUNNE, T., MELACK, J., \& HESS, L., 2001b. Water level changes in a large Amazon lake measured with spaceborne radar interferometry and altimetry. Geophysical Research Letters, 28, pp. 2671-2674.

BARRETT, B., DWYER, E., \& WHELAN, P., 2009. Soil moisture retrieval from active spaceborne microwave observations: An evaluation of current techniques. Remote Sensing, 1, pp. 210-242.

BOYLE, J., STOW, R., \& WRIGHT, P., 2000. InSAR Imaging of London Surface Movement for Structural Damage Mangament and Water Resource Conservation. In: Proceedings of the ERSEnvisat Symposium, Gothenburg, Sweden, $16^{\text {th }}-20^{\text {th }}$ October.

CARNEC, C., MASSONNET, D., \& KING, C., 1996. Two examples of the use of SAR interferometry on displacement fields of small spatial extent. Geophysical Research Letters, 23, pp. 3579-3582.

DING, X., LI, Z., ZHU, J., FENG, G., \& LONG, J., 2008. Atmospheric effects on InSAR measurements and their mitigation. Sensors, 8, pp. 5426-5448.

DONNELLAN, A., ROSEN, P., GRAF, J., LOVERRO, A., FREEMAN, A., TREUHAFT, R., OBERTO, R., SIMARD, M., RIGNOT, E., KWOK, R., XIAOQING, P., BLAIR, J.B., ABDALATI, W., RANSON, J., ZEBKER, H., HAGER, B., SHUGART, H., FAHNESTOCK, M., \& DUBAYAH, R., 2008. Deformation, Ecosystem Structure, and Dynamics of Ice (DESDynI). In: Proceedings of the IEEE Aerospace Conference, Montana, $1^{\text {st }}-8^{\text {th }}$ March, pp. 1-13.

DONNELLY, A., JONES, M.B., \& SWEENEY, J., 2004. A review of indicators of climate change for use in Ireland. International Journal of Biometeorology, 49, pp. 1-12.

FRUNEAU, B., ACHACHE, J., \& DELACOURT, C., 1996. Observation and modelling of the SaintEtienne-de-Tinée landslide using SAR interferometry. Tectonophysics, 265, pp. 181-190.

GABRIEL, A.K., GOLDSTEIN, R., \& ZEBKER, H.A., 1989. Mapping small elevation changes over large areas: Differential radar interferometry. Journal of Geophysical Research, 94, pp. 91839191.

GOLDSTEIN, R., 1995. Atmospheric limitations to repeat-track radar interferometry. Geophysical Research Letters, 22, pp. 2517-2520.

GOLDSTEIN, R., \& WERNER, C., 1998. Radar interferogram filtering for geophysical applications. Geophysical Research Letters, 25, pp. 4035-4038.

HAJNSEK, I., \& PRATS, P., 2008. Soil Moisture Estimation in time with D-InSAR. In: Proceedings of the IEEE International Geoscience and Remote Sensing Symposium (IGARSS'08), Boston, $6^{\text {th }}-$ $11^{\text {th }}$ July, pp. 546-549.

HONG, S., WDOWINSKI, S., \& KIM, S., 2010. Evaluation of TerraSAR-X observations for wetland InSAR application. IEEE Transactions on Geoscience \& Remote Sensing, 48, pp. 864-873.

KHADHRA, K., NOLAN, M., BÖRNER, T., HOUNAM, D., \& CHANDRA, M., 2006. Phase Sensitivity to Soil Moisture in Controlled Anechoic Chamber: Measurements and First Results. In: Proceedings of the German Microwave Conference - GeMiC 2006. Karlsruhe, Germany, $28^{\text {th }}-$ $30^{\text {th }}$ March.

KIM, J., LU, Z., LEE, H., SHUM, C., SWARZENSKI, C., DOYLE, T., \& BAEK, S., 2009. Integrated analysis of PALSAR/Radarsat-1 InSAR and ENVISAT altimeter data for mapping of absolute water level changes in Louisiana wetlands. Remote Sensing of the Environment, 113, pp. 23562365.

KLEES, R., \& MASSONNET, D., 1998. Deformation measurements using SAR interferometry: potential and limitations. Geologie en Mijnbouw, 77, pp. 161-176.

KRIEGER, G., HAJNSEK, I., PAPATHANASSIOU, K., EINEDER, M., YOUNIS, M., DE ZAN, F., PRATS, P., HUBER, S., WERNER, M., \& FIEDLER, H., 2009. The tandem-L mission proposal: Monitoring earth's dynamics with high resolution SAR interferometry. In: Proceedings of the IEEE Radar Conference, Pasadena, CA, $4^{\text {th }}-8^{\text {th }}$ May, pp. 1-6.

LU, Z., 2007. InSAR Imaging of Volcanic Deformation over Cloud-prone Areas-Aleutian Islands. Photogrammetric Engineering and Remote Sensing, 73, pp. 245-257. 
LU, Z., \& KWOUN, O., 2008. Radarsat-1 and ERS InSAR analysis over southeastern coastal Louisiana: Implications for mapping water-level changes beneath swamp forests. IEEE Transactions on Geoscience \& Remote Sensing, 46, pp. 2167-2184.

MASSONNET, D., \& FEIGL, K., 1995. Satellite radar interferometric map of the coseismic deformation field of the $M=6.1$ Eureka Valley, California earthquake of May 17, 1993. Geophysical Research Letters, 22, pp. 1541-1544.

MASSONNET, D., \& FEIGL, K., 1998. Radar interferometry and its application to changes in the Earth's surface. Reviews of Geophysics, 36, pp. 441-500.

MASSONNET, D., ROSSI, M., CARMONA, C., ADRAGNA, F., PELTZER, G., FEIGL, K., \& RABAUTE, T., 1993. The displacement field of the Landers earthquake mapped by radar interferometry. Nature, 364, pp. 138-142.

MORRISON, K., NOLAN, M., BENNETT, J., \& BLACKNELL, D., 2008. A laboratory investigation into soil moisture estimation using DInSAR. In: Proceedings of the 2008 International Conference on Radar, Adelaide, SA, $2^{\text {nd }}-5^{\text {th }}$ September, pp. 288-291.

NG, A., CHANG, H., GE, L., RIZOS, C., \& OMURA, M., 2009. Assessment of radar interferometry performance for ground subsidence monitoring due to underground mining. Earth, Planets and Space, 61, pp. 733-745.

NG, A.H.-M., GE, L., YAN, Y., LI, X., CHANG, H.-C., ZHANG, K., \& RIZOS, C., 2010. Mapping accumulated mine subsidence using small stack of SAR differential interferograms in the Southern coalfield of New South Wales, Australia. Engineering Geology, 115, pp. 1-15.

NOLAN, M., \& FATLAND, D.R., 2003. Penetration depth as a DInSAR observable and proxy for soil moisture. IEEE Transactions on Geoscience \& Remote Sensing, 41, pp. 532-537.

NOLAN, M., FATLAND, D.R., \& HINZMAN, L., 2003. DInSAR measurement of soil moisture. IEEE Transactions on Geoscience \& Remote Sensing, 41, pp. 2802-2813.

PELTZER, G., ROSEN, P., ROGEZ, F., \& HUDNUT, K., 1998. Poro-elastic rebound along the Landers 1992 earthquake surface rupture. Journal of Geophysical Research, 103, pp. 30131-30145.

PRATS, P., SCHEIBER, R., MOREIRA, A., REIGBER, A., \& MALLORQUI, J.J., 2007. Advanced DInSAR techniques applied to a time series of airborne SAR data. In: Proceedings of the IEEE International Geoscience and Remote Sensing Symposium (IGARSS'07), Barcelona, $23^{\text {rd }}-28^{\text {th }}$ July, pp. 4874-4877.

RABUS, B., WEHN, H., \& NOLAN, M., 2010. The Importance of Soil Moisture and Soil Structure for InSAR Phase and Backscatter, as Determined by FDTD Modelling. IEEE Transactions on Geoscience \& Remote Sensing, 48, pp. 2421-2429.

REIGBER, A., \& SCHEIBER, R., 2003. Airborne differential SAR interferometry: First results at Lband. IEEE Transactions on Geoscience \& Remote Sensing, 41, pp. 1516-1520.

ROTT, H., SCHEUCHL, B., SIEGEL, A., \& GRASEMANN, B., 1999. Monitoring very slow slope movements by means of SAR interferometry: A case study from a mass waste above a reservoir in the Ötztal Alps, Austria. Geophysical Research Letters, 26, pp. 1629-1632.

SEYFRIED, M., \& MURDOCK, M., 2004. Measurement of soil water content with a 50-MHz soil dielectric sensor. Soil Science Society of America Journal, 68, pp. 394-403.

VAN OEVELEN, P., 1998. Soil moisture variability: a comparison between detailed field measurements and remote sensing measurement techniques. Hydrological Sciences, 43, pp. 511-520.

WEGMULLER, U., STROZZI, T., \& TOSI, L., 2000. ERS and ENVISAT Differential SAR Interferometry for Subsidence Monitoring. In: Proceedings of the ERS-Envisat Symposium, Gothenburg, Sweden, $16^{\text {th }}-20^{\text {th }}$ October.

WIGNERON, J., CALVET, J., PELLARIN, T., VAN DE GRIEND, A., BERGER, M., \& FERRAZZOLI, P., 2003. Retrieving near-surface soil moisture from microwave radiometric observations: current status and future plans. Remote Sensing of the Environment, 85, pp. 489-506.

XU, W., \& CUMMING, I., 1999. A region-growing algorithm for InSAR phase unwrapping. IEEE Transactions on Geoscience \& Remote Sensing, 37, pp. 124-134.

XU, Z., WU, J., \& WU, Z., 2004. A survey of ionospheric effects on space-based radar. Waves in Random and Complex Media, 14, pp. 189-273.

ZEBKER, H., \& GOLDSTEIN, R., 1986. Topographic mapping from interferometric synthetic aperture radar observations. Journal of Geophysical Research, 91, pp. 4993-4999.

ZEBKER, H., ROSEN, P., \& EARTH, J., 1997. Atmospheric artifacts in interferometric SAR surface deformation and topographic maps. Journal of Geophysical Research Solid Earth, 102, pp. 75477563. 
TABLE 1: COMPARISON OF ENVISAT ASAR AND ALOS PALSAR

\begin{tabular}{|c|c|c|c|}
\hline & ASAR & \multicolumn{2}{|l|}{ PALSAR } \\
\hline Mission Duration & Mar 2002-May 2012 & \multicolumn{2}{|c|}{ Jan 2006-May 2011} \\
\hline Wavelength & $5.6 \mathrm{~cm}$ & \multicolumn{2}{|l|}{$23.6 \mathrm{~cm}$} \\
\hline Altitude & $800 \mathrm{~km}$ & \multicolumn{2}{|l|}{$692 \mathrm{~km}$} \\
\hline Repeat Cycle & 35 days & \multicolumn{2}{|l|}{46 days } \\
\hline \multirow[t]{2}{*}{ Polarisation } & HH,VV,HH/HV, & \multicolumn{2}{|l|}{ HH, HH/HV, } \\
\hline & $\mathrm{HH} / \mathrm{VV}, \mathrm{VV} / \mathrm{VH}$ & \multicolumn{2}{|c|}{ HH/VV/VH/HV } \\
\hline Incidence Angle & $\sim 15-45^{\circ}$ & \multicolumn{2}{|l|}{$\sim 38^{\circ}$} \\
\hline Bandwidth & $16 \mathrm{MHz}$ & FBS: $28 \mathrm{MHz}$ & FBD: $14 \mathrm{MHz}$ \\
\hline Critical Baseline & $\mathrm{I} 1: 745 \mathrm{~m}$ & FBS: $13.1 \mathrm{~km}$ & FBD: $6.5 \mathrm{~km}$ \\
\hline
\end{tabular}


TABLE 2: CHARACTERISTICS OF ASAR AND PALSAR DINSAR PAIRS

\begin{tabular}{|c|c|c|c|c|c|c|c|}
\hline $\begin{array}{l}\text { Pair } \\
\#\end{array}$ & Master & Slave & $\begin{array}{l}\text { Day } \\
\text { diff }\end{array}$ & $\begin{array}{c}\perp \text { Baseline } \\
\text { Diff (m) }\end{array}$ & $\begin{array}{l}\text { Track/ } \\
\text { Frame }\end{array}$ & $\begin{array}{l}\text { Polari- } \\
\text { sation }\end{array}$ & $\begin{array}{c}\text { Doppler } \\
\text { Centroid } \\
\text { Diff }(\mathrm{Hz})\end{array}$ \\
\hline & ASAR APS & & & & & & \\
\hline 1. & $06 / 07 / 2007$ & $10 / 08 / 2007$ & 35 & 75 & $352 / 2547$ & $\mathrm{HH}$ & 4.8 \\
\hline 2. & 06/07/2007 & $10 / 08 / 2007$ & 35 & 75 & $352 / 2547$ & HV & 4.8 \\
\hline 3. & $01 / 06 / 2008$ & 06/07/2008 & 35 & 187 & $80 / 2558$ & $\mathrm{HH}$ & 1.3 \\
\hline 4. & 01/06/2008 & 06/07/2008 & 35 & 187 & $80 / 2558$ & HV & 1.3 \\
\hline $5 . *$ & $26 / 08 / 2008$ & $04 / 11 / 2008$ & 70 & 43 & $309 / 2560$ & $\mathrm{HH}$ & 26.3 \\
\hline 6.* & $26 / 08 / 2008$ & $04 / 11 / 2008$ & 70 & 43 & $309 / 2560$ & VV & 26.3 \\
\hline 7.* & $04 / 11 / 2008$ & $09 / 12 / 2008$ & 35 & 571 & $309 / 2560$ & $\mathrm{HH}$ & -38.5 \\
\hline 8. & 05/06/2009 & $10 / 07 / 2009$ & 35 & 65 & $352 / 2555$ & $\mathrm{HH}$ & -34.4 \\
\hline 9. * & $11 / 08 / 2009$ & 20/10/2009 & 70 & 238 & $309 / 2560$ & $\mathrm{HH}$ & 31.1 \\
\hline 10. $*$ & $20 / 10 / 2009$ & $24 / 11 / 2009$ & 35 & 520 & $309 / 2560$ & $\mathrm{HH}$ & -27.4 \\
\hline \multirow[t]{2}{*}{ 11.* } & $20 / 10 / 2009$ & $24 / 11 / 2009$ & 35 & 520 & $309 / 2560$ & HV & -27.4 \\
\hline & PALSAR FBD & & & & & & \\
\hline 12. & $15 / 07 / 2007$ & $15 / 10 / 2007$ & 92 & 974 & $3 / 1030$ & $\mathrm{HH}$ & 30.7 \\
\hline 13. & $15 / 07 / 2007$ & $15 / 10 / 2007$ & 92 & 974 & $3 / 1030$ & HV & 30.7 \\
\hline 14. & $15 / 07 / 2007$ & $30 / 08 / 2007$ & 46 & 838 & $3 / 1030$ & $\mathrm{HH}$ & 45.8 \\
\hline 15. & $15 / 07 / 2007$ & $30 / 08 / 2007$ & 46 & 838 & $3 / 1030$ & HV & 45.8 \\
\hline 16. & $30 / 08 / 2007$ & $15 / 10 / 2007$ & 46 & 537 & $3 / 1030$ & $\mathrm{HH}$ & -15.1 \\
\hline 17. & $30 / 08 / 2007$ & $15 / 10 / 2007$ & 46 & 537 & $3 / 1030$ & HV & -15.1 \\
\hline 18. & $20 / 07 / 2009$ & 04/09/2009 & 46 & 604 & $3 / 1030$ & $\mathrm{HH}$ & 5.5 \\
\hline 19. & 20/07/2009 & 04/09/2009 & 46 & 604 & $3 / 1030$ & HV & 5.5 \\
\hline 20. & 20/07/2009 & 20/10/2009 & 92 & 1064 & $3 / 1030$ & $\mathrm{HH}$ & 9.9 \\
\hline \multirow[t]{2}{*}{21.} & $04 / 09 / 2009$ & $20 / 10 / 2009$ & 46 & 465 & $3 / 1030$ & $\mathrm{HH}$ & 4.4 \\
\hline & PALSAR FBS & & & & & & \\
\hline 22. & $01 / 03 / 2008$ & $16 / 04 / 2008$ & 46 & 597 & $3 / 1030$ & $\mathrm{HH}$ & -28.6 \\
\hline 23. & $15 / 01 / 2008$ & $01 / 03 / 2008$ & 46 & 802 & $3 / 1030$ & $\mathrm{HH}$ & 17.4 \\
\hline \multirow[t]{2}{*}{24.} & $15 / 01 / 2008$ & $16 / 04 / 2008$ & 92 & 1156 & $3 / 1030$ & $\mathrm{HH}$ & -11.2 \\
\hline & FBD2FBS & & & & & & \\
\hline 25 . & $15 / 01 / 2008$ & $15 / 10 / 2007$ & 92 & 706 & $3 / 1030$ & $\mathrm{HH}$ & 1.7 \\
\hline 26. & $01 / 03 / 2008$ & $01 / 06 / 2008$ & 92 & 886 & $3 / 1030$ & $\mathrm{HH}$ & -55.1 \\
\hline 27. & $16 / 04 / 2008$ & $01 / 06 / 2008$ & 46 & 419 & $3 / 1030$ & $\mathrm{HH}$ & -26.4 \\
\hline
\end{tabular}


TABLE 3: OVERALL CORRELATION RESULTS (SHADED) AND CORRELATION RESULTS FOR EACH INTERFEROMETRIC PAIR

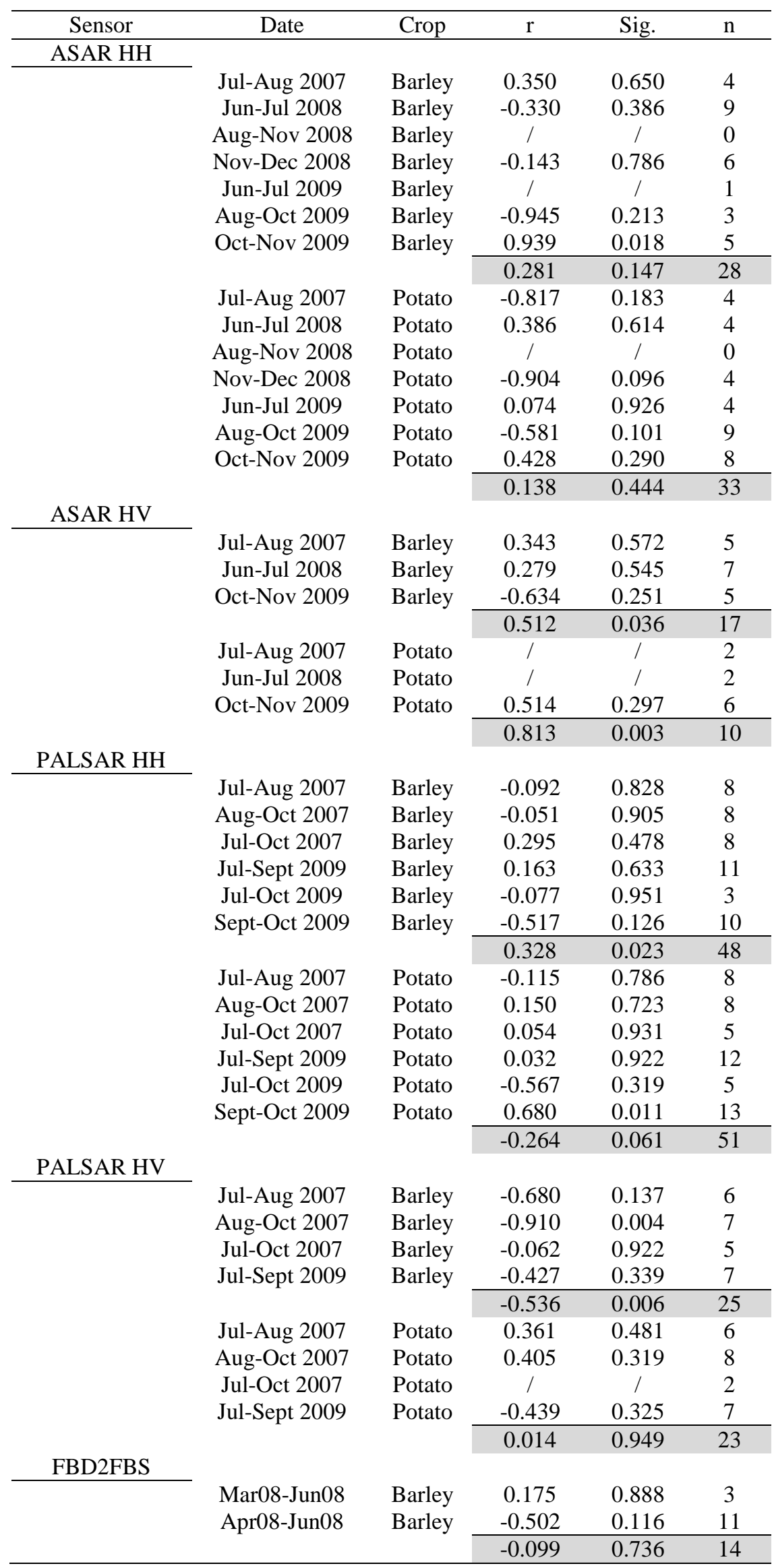


TABLE 4: METEOROLOGICAL CONDITIONS AT TIME OF ACQUISITIONS

\begin{tabular}{|c|c|c|c|c|c|}
\hline Image & Date & Temp $\left({ }^{\circ} \mathrm{C}\right)$ & $\begin{array}{c}\text { Accumulated } \\
3 \text { day Precip } \\
(\mathrm{mm})\end{array}$ & $\begin{array}{c}\text { Relative } \\
\text { Humidity } \\
(\%)\end{array}$ & $\begin{array}{c}\text { Wind speed } \\
\text { (knots) }\end{array}$ \\
\hline \multicolumn{6}{|c|}{ ASAR APS } \\
\hline 1. & $06 / 07 / 2007$ & 16.0 & 6.5 & 63 & 18.5 \\
\hline 2. & $10 / 08 / 2007$ & 14.4 & 1.2 & 95 & 7 \\
\hline 3. & $01 / 06 / 2008$ & 18.3 & 1.8 & 57 & 3 \\
\hline 4. & $06 / 07 / 2008$ & 13.5 & 47.2 & 94 & 12 \\
\hline 5. & $26 / 08 / 2008$ & 15.9 & 6.2 & 94 & 12.5 \\
\hline 6. & $04 / 11 / 2008$ & 7.6 & 0 & 88 & 7 \\
\hline 7. & $09 / 12 / 2008$ & 6.0 & 5.1 & 84 & 13.5 \\
\hline 8. & 05/06/2009 & 14.2 & 0 & 80 & 7.5 \\
\hline 9. & $10 / 07 / 2009$ & 13.7 & 4.7 & 95 & 6 \\
\hline 10. & $11 / 08 / 2009$ & 17.4 & 7.8 & 77 & 7 \\
\hline 11. & 20/10/2009 & 12.4 & 16.5 & 88 & 8 \\
\hline 12. & $24 / 11 / 2009$ & 11.4 & 16.6 & 97 & 30.5 \\
\hline \multicolumn{6}{|c|}{ PALSAR FBD } \\
\hline 13. & $15 / 7 / 2007$ & 13.2 & 24.8 & 100 & 5 \\
\hline 14. & $30 / 8 / 2007$ & 14.1 & 0 & 93 & 10.5 \\
\hline 15. & $15 / 10 / 2007$ & 13.4 & 1.2 & 98 & 12.5 \\
\hline 16. & $01 / 06 / 2008$ & 13.1 & 1.4 & 94 & 4 \\
\hline 17. & 20/07/2009 & 13.1 & 0.1 & 96 & 7 \\
\hline 18. & $04 / 09 / 2009$ & 10.2 & 15.3 & 91 & 7.5 \\
\hline 19. & $20 / 10 / 2009$ & 11.6 & 11.6 & 82 & 16 \\
\hline \multicolumn{6}{|c|}{ PALSAR FBS } \\
\hline 20. & $1 / 3 / 2008$ & 4.4 & 13.5 & 86 & 9.5 \\
\hline 21. & $15 / 1 / 2008$ & 11.4 & 1 & 95 & 16 \\
\hline 22. & $16 / 4 / 2008$ & 8.3 & 0 & 73 & 17.5 \\
\hline
\end{tabular}




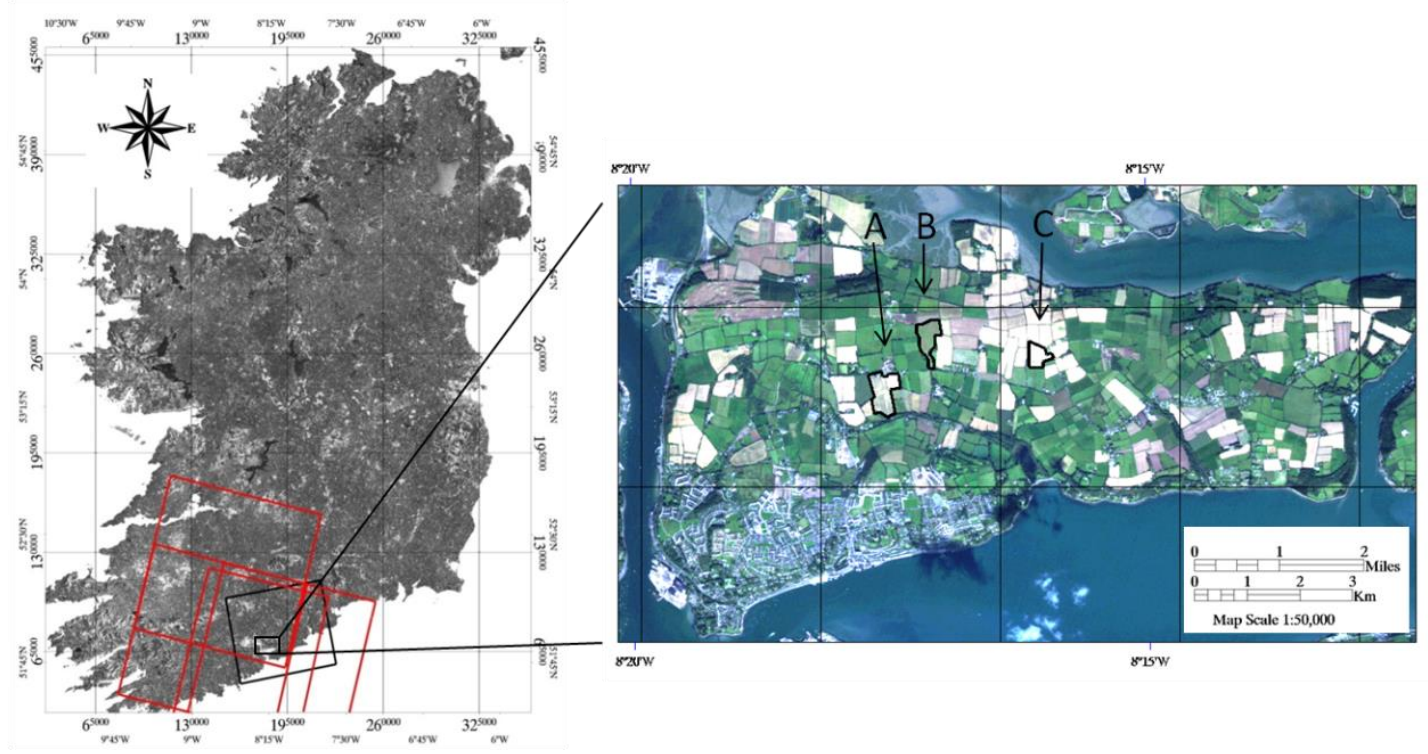

Figure 1: Descending ASAR (red polygon) and ascending PALSAR (black polygon) imaged swaths over the Cork study site. The image on the right is an AVNIR-2 subset displaying the location of each of the three test fields situated on Great Island, Cobh, Cork. 
(a)

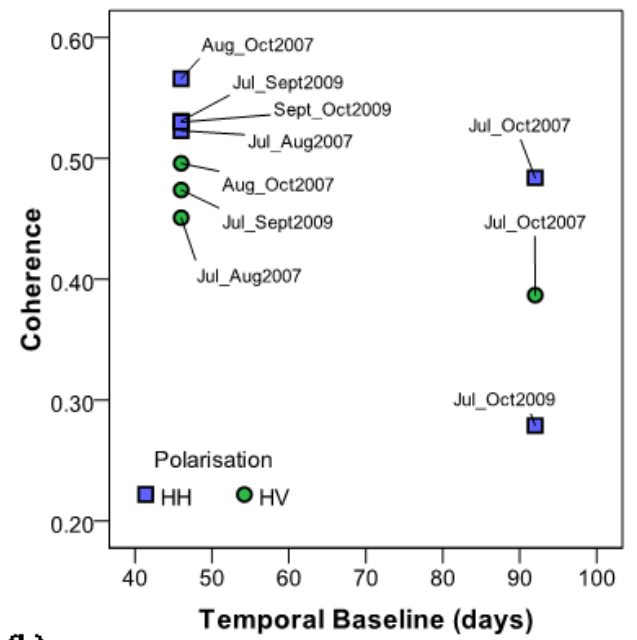

(b)

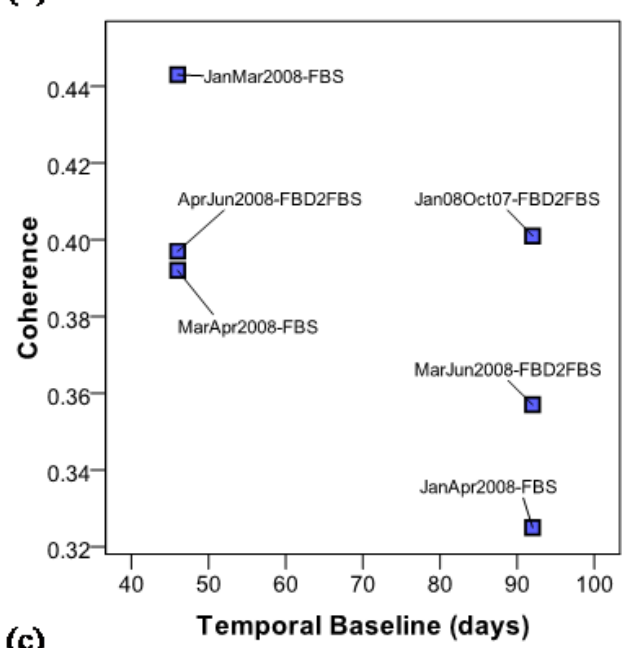

(c)

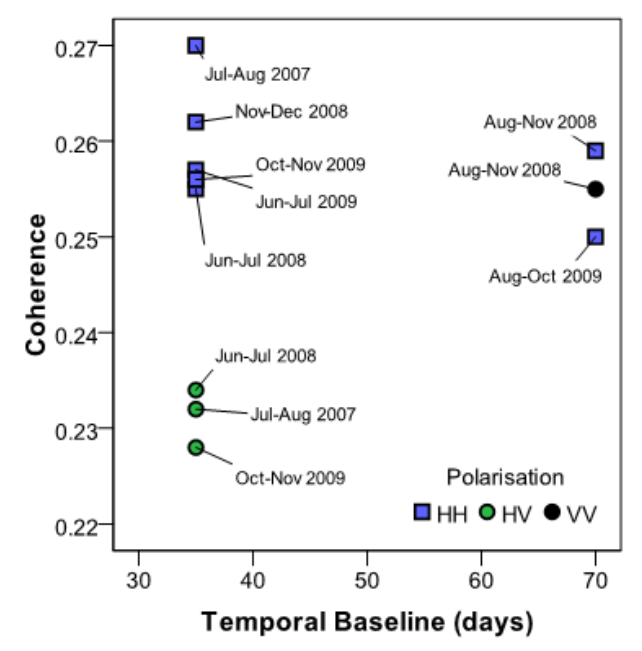

(ii)
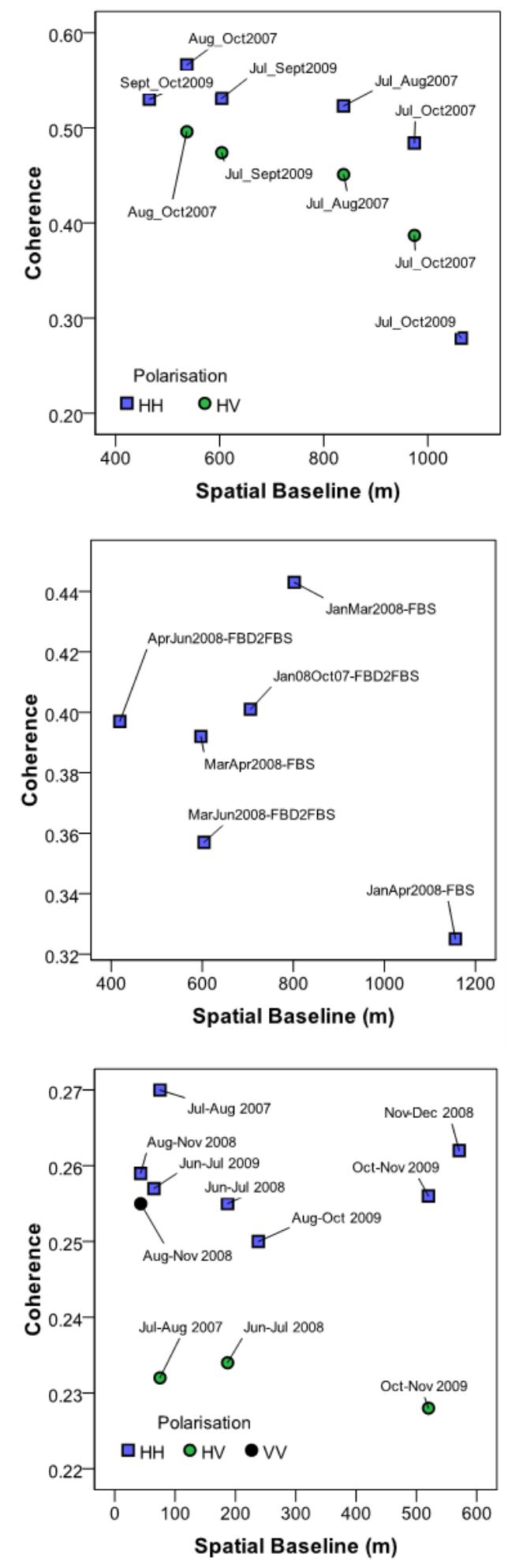

Figure 2: Mean coherence values over study area with respect to (i) temporal baseline and (ii) spatial (perpendicular) baseline for (a) FBD pairs, (b) FBS \& FBD2FBS pairs, and (c) ASAR pairs. In all cases, blue boxes indicate $\mathrm{HH}$ polarisation coherence; green 
circles indicate HV polarisation coherence and black circles indicate VV polarisation coherence. 

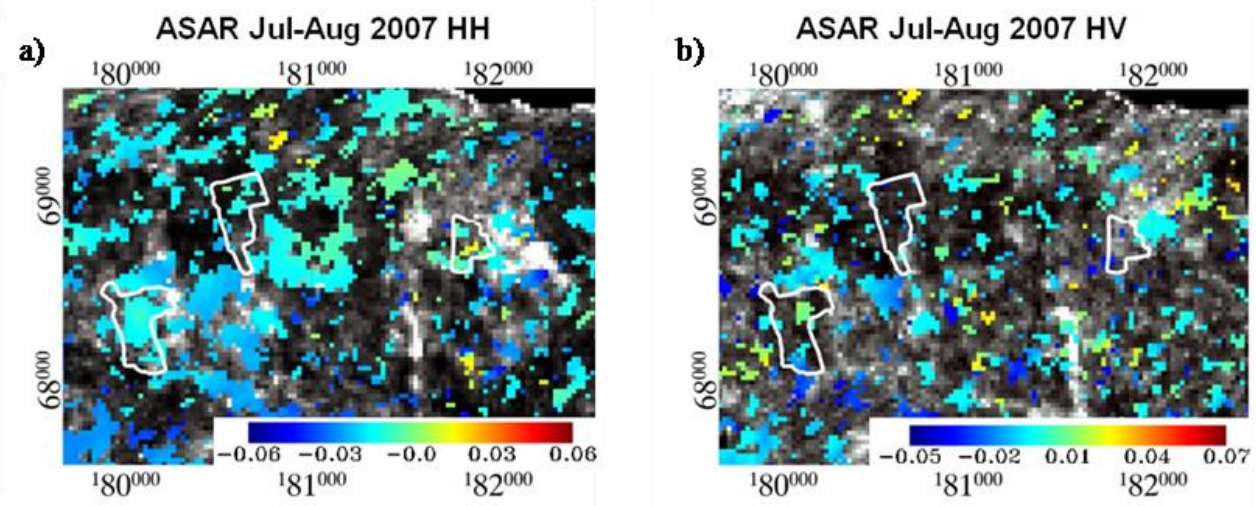

c)

ASAR Jun-Jul $2008 \mathrm{HH}$

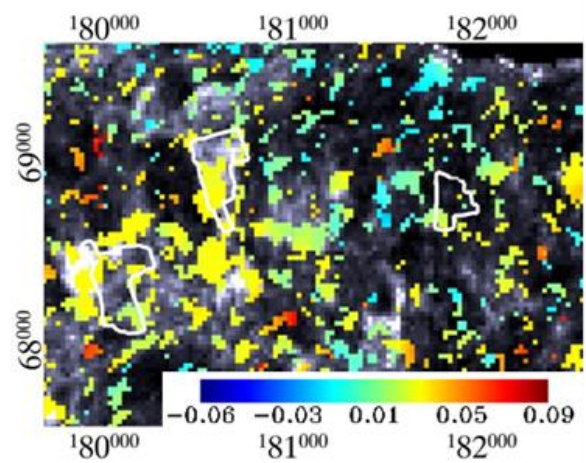

d) ASAR Jun-Jul $2008 \mathrm{HV}$
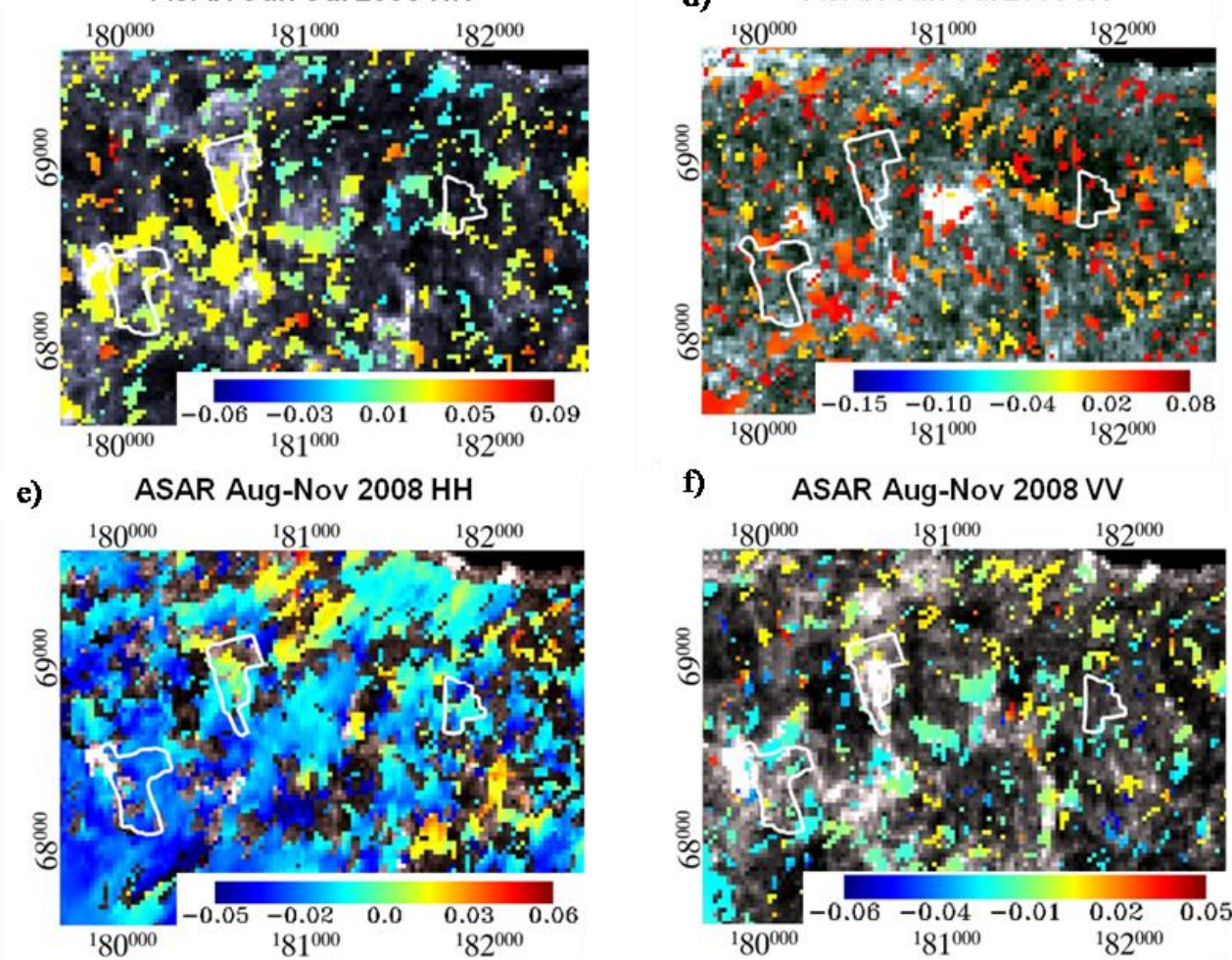

f) ASAR Aug-Nov $2008 \mathrm{VV}$

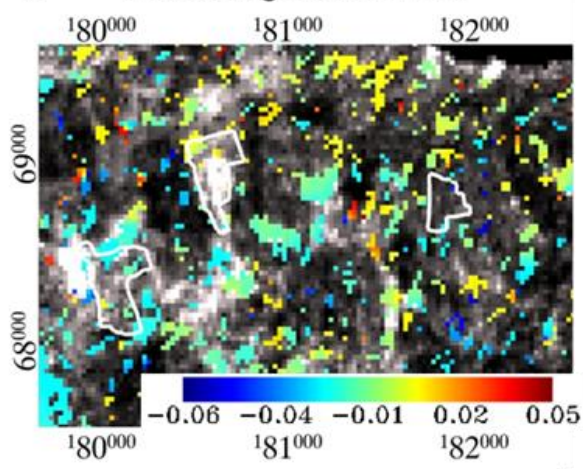

g) ASAR Nov-Dec $2008 \mathrm{HH}$

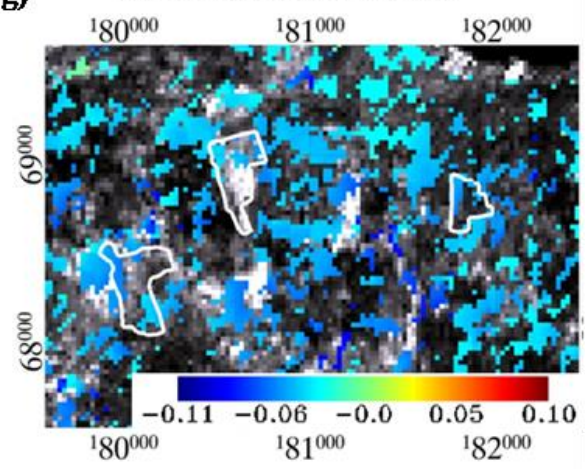

h) ASAR Jun-Jul $2009 \mathrm{HH}$

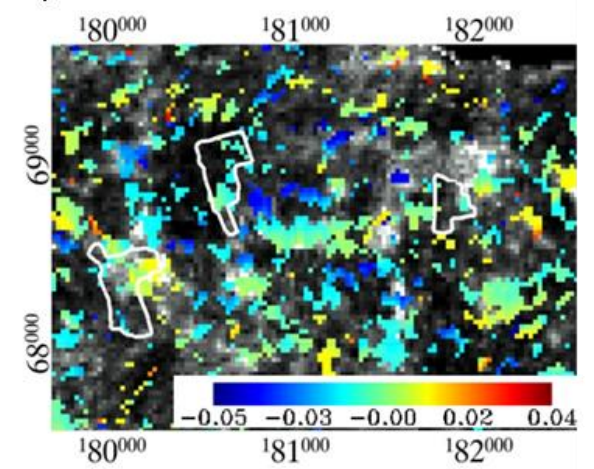



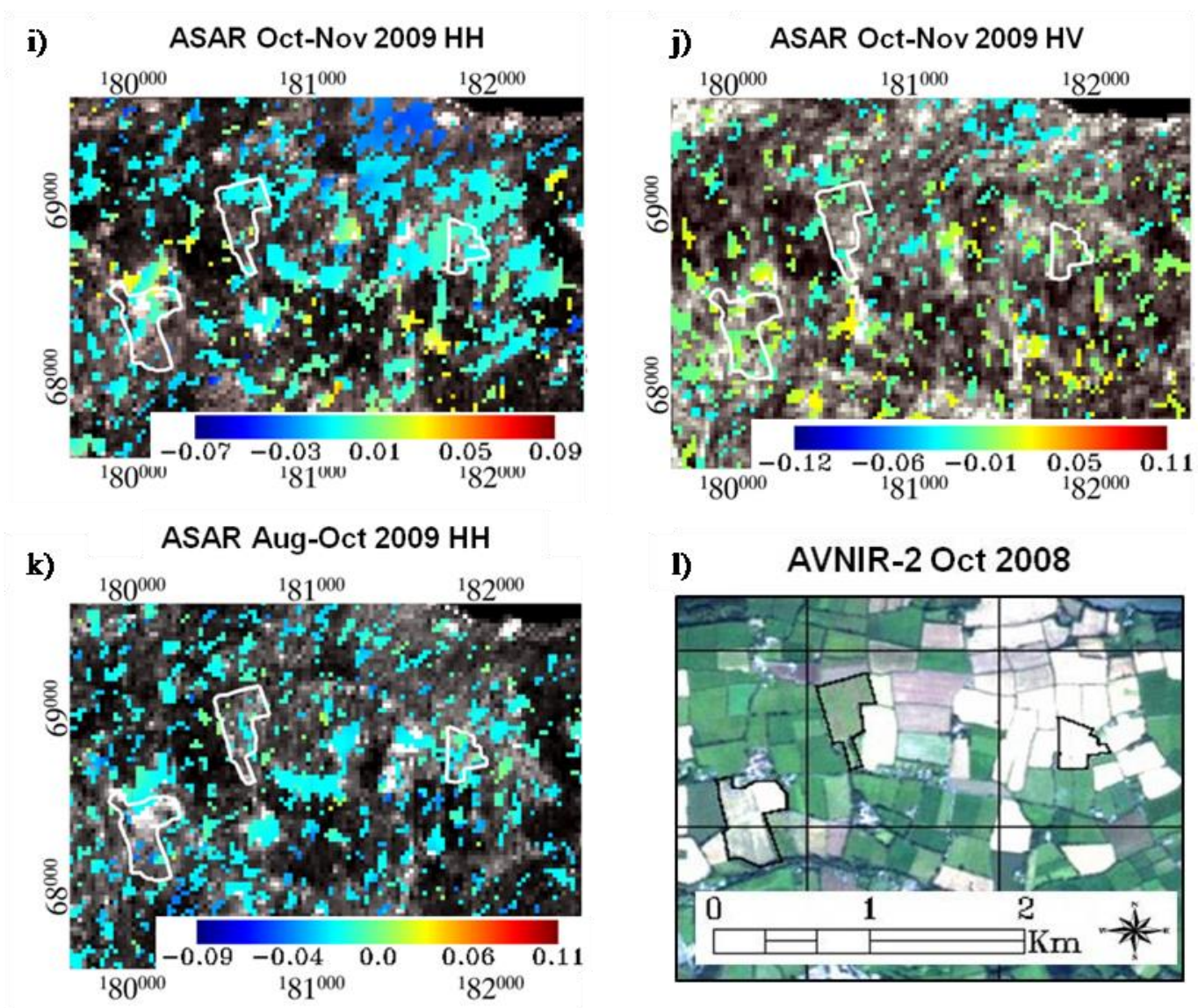

\section{1) AVNIR-2 Oct 2008}

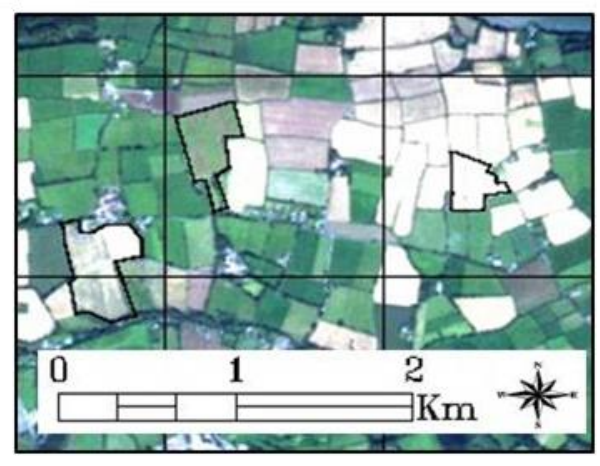

Figure 3: ASAR vertical displacement maps. Pixels with coherence $<0.3$ have been excluded from the analysis. Background image in each plot is the mean backscatter intensity of the two SLCs used to generate the interferogram. White polygons represent the location of the three test fields. Displacements are colour coded (blue-green-yellowred) according to the colour ramp in each plot and are measured in metres. 
a)

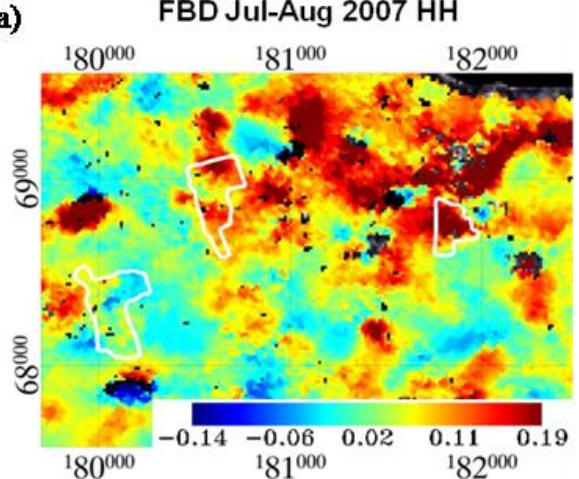

c)

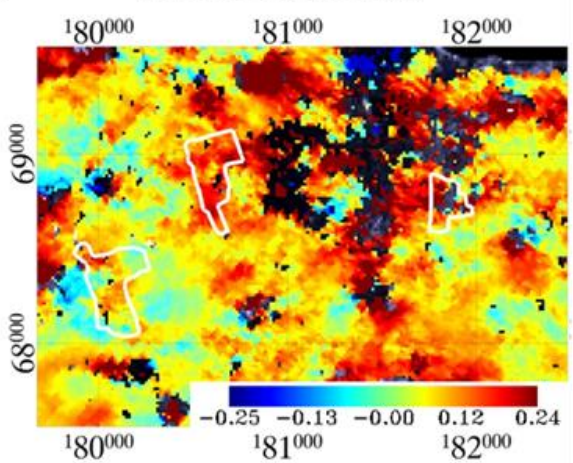

e)

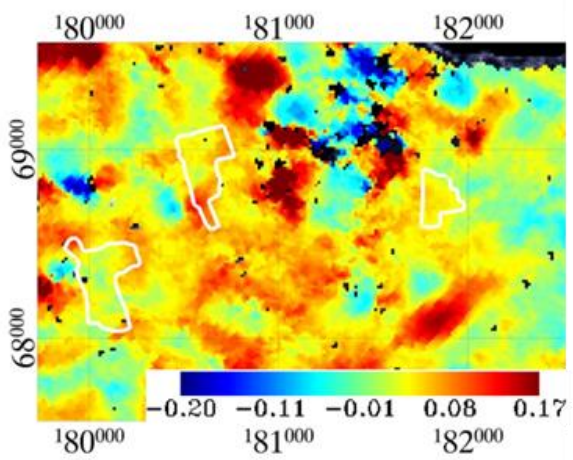

g)

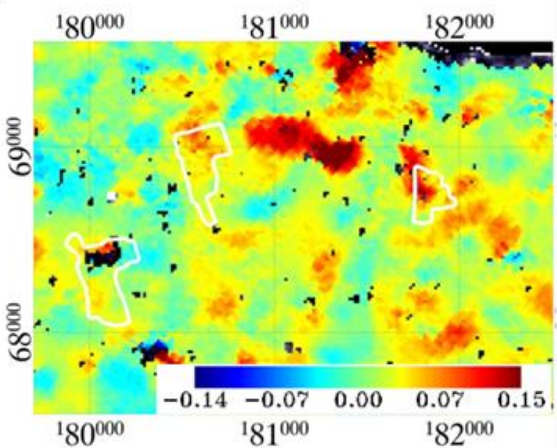

b) FBD Jul-Aug $2007 \mathrm{HV}$

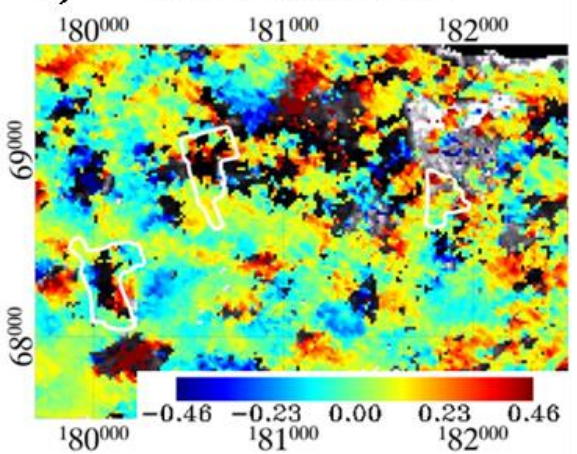

d) FBD Jul-Oct $2007 \mathrm{HV}$

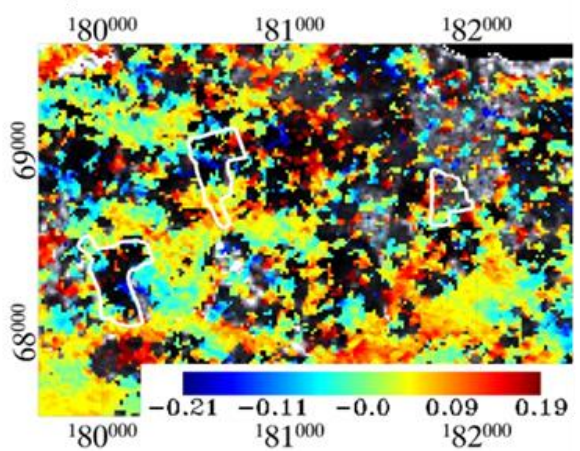

f) FBD Aug-Oct $2007 \mathrm{HV}$

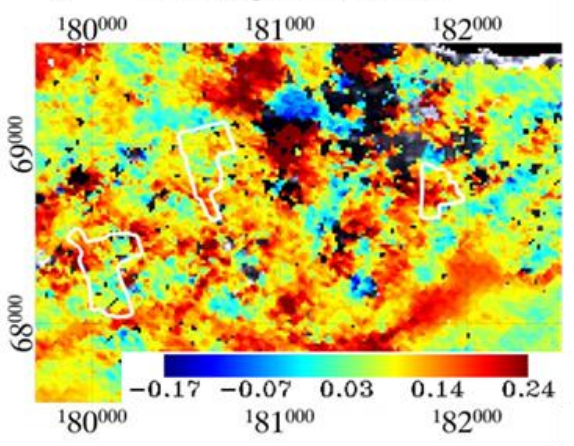

h) FBD Jul-Sept $2009 \mathrm{HV}$

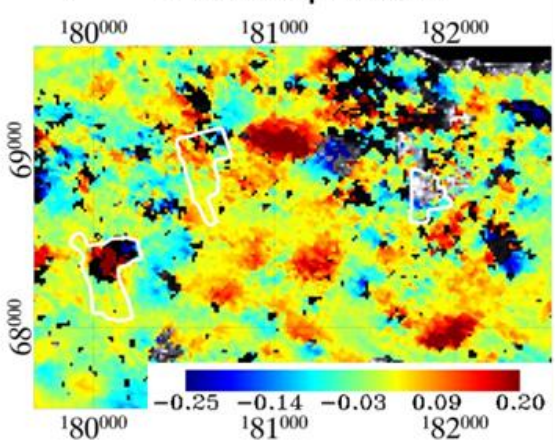


i)

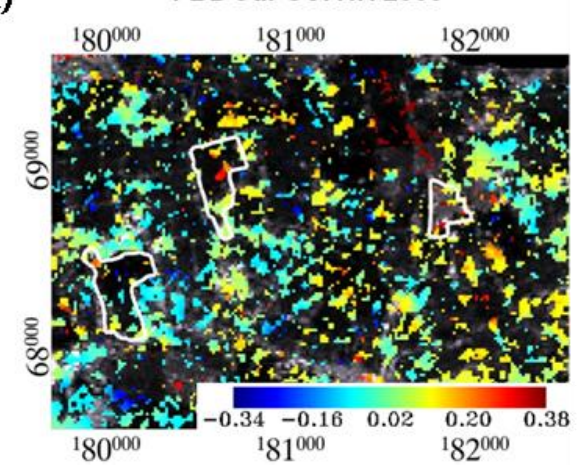

k)

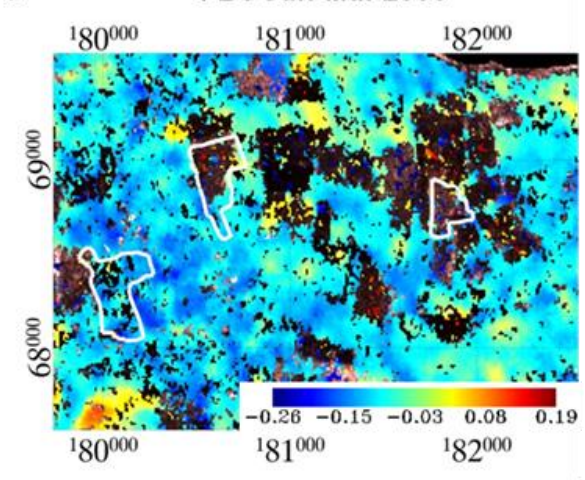

m)

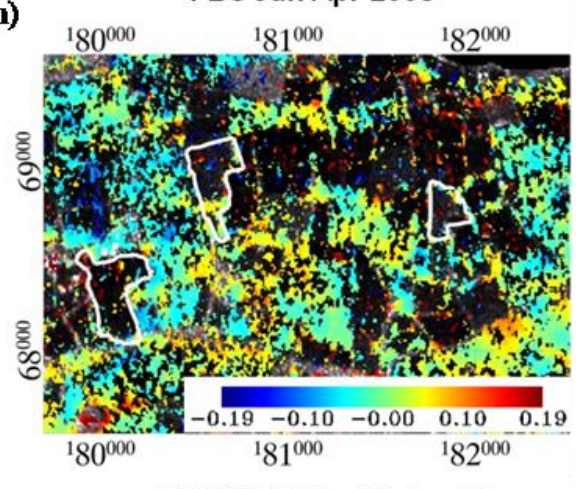

o)

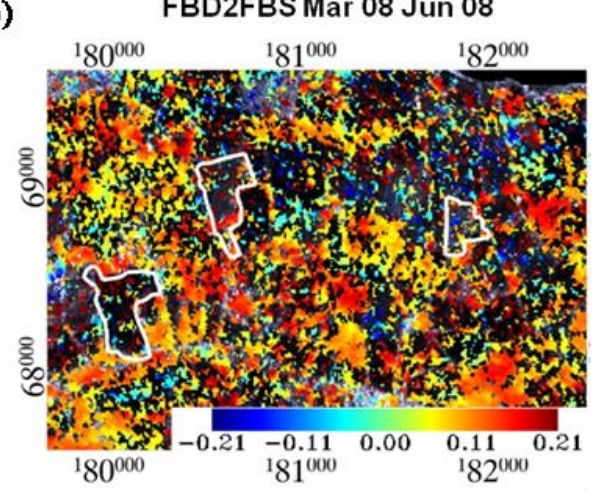

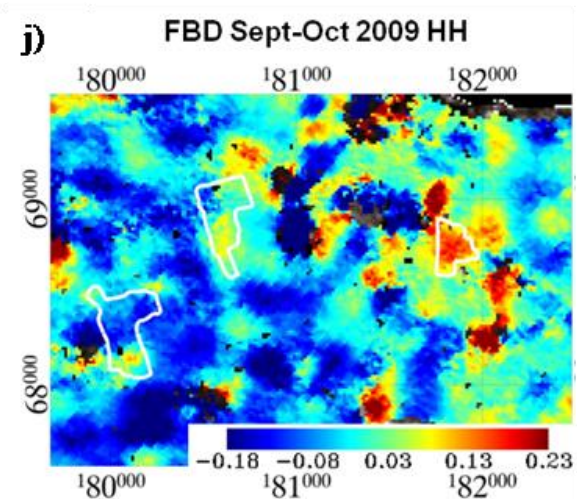

1) FBS Mar Apr 2008

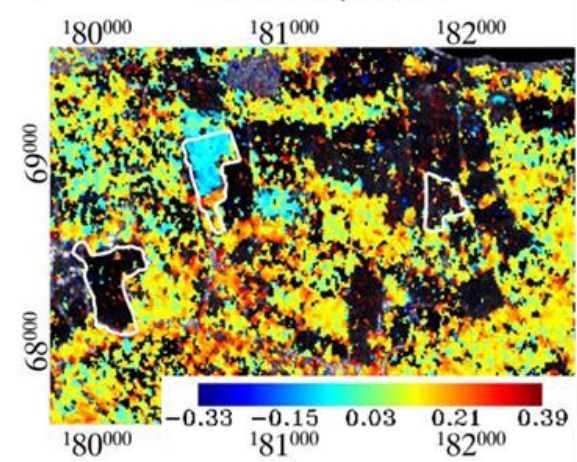

FBD2FBS Jan08 Oct 07

n)

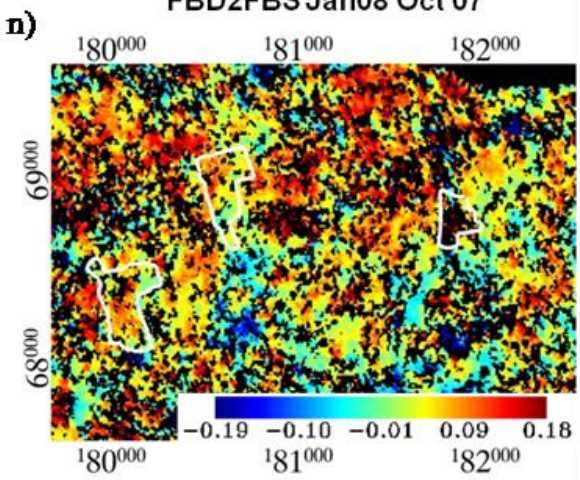

p)

FBD2FBS Apr 08 Jun 08

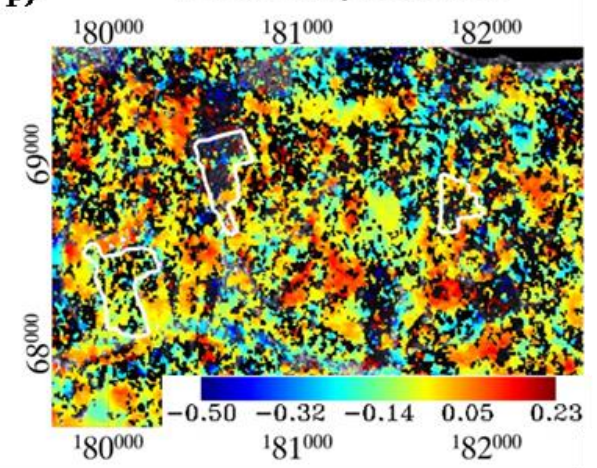

Figure 4: (a)-(j) PALSAR FBD, (k)-(m) PALSAR FBS, and (n)-(p) PALSAR FBD2FBS surface displacement maps. One colour cycle (blue-green-yellow-red) represents the surface displacement between the ground surface and radar antenna between the two dates of each pair. 

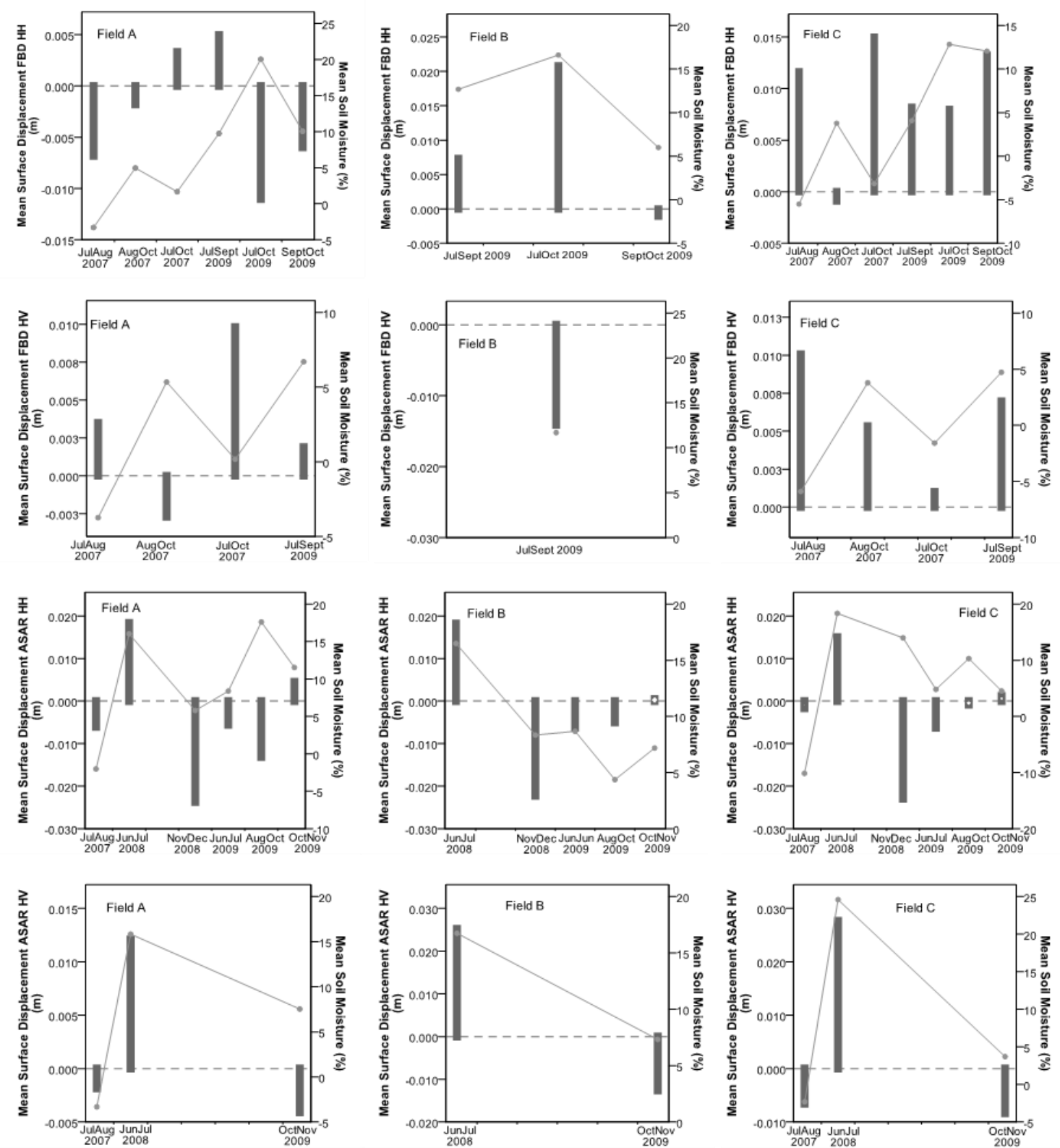

Figure 5: Comparison of C- and L-band mean surface displacement (primary y-axis) with in-situ mean soil moisture change (secondary $y$-axis) as a function of time (x-axis). Dashed horizontal line represents zero surface displacement and the continuous line signifies measured soil moisture where positive values indicate a soil moisture increase between the $1^{\text {st }}$ and $2^{\text {nd }}$ acquisitions and negative values signal a soil moisture decrease between acquisitions. Each column represents the three different test fields. 
